\title{
Conhecendo a Produção de Normas Técnicas em Compatibilidade Eletromagnética
}

\author{
Gabriel C. Clemente, César J. B. Pagan.
}

\section{Resumo}

Estudo sobre os aspectos técnicos, socioeconômicos e éticos em compatibilidade eletromagnética.

\begin{abstract}
Palavras-chave:
Compatibilidade eletromagnética, sistema normativo, eletromagnetismo.
\end{abstract}

\section{Introdução}

Tornar um sistema imune à presença de outro sistema, seja ele natural ou construído, até o limite em que 0 funcionamento do primeiro não esteja comprometido pela interferência, de natureza eletromagnética, do segundo, ao mesmo tempo em que este não produza interferência em outros equipamentos, é, em suma, o objetivo da compatibilidade eletromagnética (usualmente utiliza-se EMC do inglês Electromagnetic Compatibility).

O intuito do trabalho em questão é desenvolver um estudo completo acerca desta área da engenharia elétrica, que não se limita a analisar somente ensaios e a teoria eletromagnética, âmago teórico por trás dos problemas em EMC, mas também aspectos socioeconômicos e éticos, rigorosamente associados a um sistema normativo.

\section{Resultados e Discussão}

Criar normas para o setor industrial permite que os fabricantes possam estabelecer métodos de produção, ferramentas e processos reprodutíveis. Um bom sistema normativo, internacionalizado e institucionalmente robusto é um indutor de inovação e gerador de oportunidades.

Compreendidos os conceitos básicos, o cerne desse trabalho é analisar a produção de normas técnicas em EMC. Dito isso, não há nada que beneficie mais essa análise do que participar de um grupo de estudo cujo objetivo é nacionalizar uma norma. Uma das finalidades do comitê CE 003109002 "Limites e Métodos de Medição de Rádio Perturbação em Equipamentos para Tecnologia da Informação", do qual participo desde meados de outubro de 2018 foi elaborar a norma ABNT NBR IEC CISPR 15, equivalente à versão 9.0 (2018) da IEC.

Além da contribuição na ABNT NBR IEC CISPR 15, o comitê CE $003 \quad 077 \quad 001 \quad$ "Compatibilidade Eletromagnética", o qual também integro, destinou a mim a tarefa de realizar a tradução técnica, primeira etapa da nacionalização de uma norma, da ABNT NBR IEC 61006-3.

A ABNT NBR IEC CISPR 15 é um documento que apresenta os limites e métodos de medição das características de radioperturbação de equipamentos elétricos de iluminação. Aplica-se à emissão conduzida e radiada. Já a ABNT NBR IEC 6100-6-3 mostra padrões de emissão para ambientes residenciais, comerciais e industriais leves. De modo geral, o objetivo é definir as exigências do ensaio de emissão para um grupo de sistemas listados na norma em relação à perturbações contínuas e transitórias, conduzidas e irradiadas.

Um problema clássico, e que ilustra muito bem os conceitos em EMC, é o ruído que o contato das escovas com as bobinas do rotor de uma máquina de corrente contínua produzem quando a comutação não é feita na posição correta.

Junto à equipe do Instituto de Pesquisas Eldorado, tive a oportunidade de participar de um ensaio completo de emissão conduzida e radiada de lâmpadas LED, assunto abordado na CISPR 15 e nos debates dos quais participei durante as reuniões da CE 003109 002. O objetivo desse experimento foi explorar os requisitos, estabelecidos na ABNT NBR IEC CISPR 15 versão 2013, que devem ser atendidos pelas lâmpadas LED, visando, sobretudo, a compatibilidade eletromagnética delas. Com foco na emissão radiada, foram analisados dois métodos de medição que, segundo a norma, são equivalentes.

Também no Instituto de Pesquisas Eldorado foi elaborado um estudo que comprovou a interferência do ruído eletromagnético produzido por eletrodomésticos em uma rede de telecomunicações, evidenciando mais uma vez a importância de um sistema normativo e dos estudos em EMC.

\section{Conclusões}

Os objetivos deste projeto foram satisfatoriamente alcançados. Em suma, foram desenvolvidos os conceitos em EMC que proporcionaram compreensão plena do problema relacionado à máquina de corrente contínua. Além disto, o conhecimento obtido na participação do processo de elaboração da ABNT NBR IEC CISPR 15 foi utilizado nas etapas de nacionalização da ABNT NBR IEC 6100-6-3. Ainda relacionado às normas técnicas, foi observado na prática o uso da ABNT NBR IEC CISPR 15 versão 2013 nos ensaios realizados no Instituto de Pesquisas Eldorado. Ademais, destaca-se o impacto socioeconômico e, consequentemente, a importância de um sistema normativo sólido, sobretudo no setor industrial, assim como as vantagens de o conhecer intimamente. Finalizamos com um estudo realizado no Instituto de Pesquisas Eldorado que evidencia a grande importância do tema abordado.

Podemos alegar então, que o trabalho elaborado é bastante equilibrado na área de introdução a EMC, além de seguir uma linha de raciocínio lógica.

\footnotetext{
1 Paul, Clayton. Introduction to Electromagnetic Compatibility, 2nd Edition, Wiley (2006)

${ }^{2}$ Ott, W. Henry, Electromagnetic Compatibility Engineering, Wiley (2009)

${ }^{3}$ Notas de aula do Prof. Dr. César José Bonjuani Pagan, Introdução a EMC

${ }^{4}$ ABNT Coleção.
} 